\title{
Cohabitation and marriage in Britain since the 1970s
}

Éva Beaujouan and Máire Ní Bhrolcháin

ESRC Centre for Population Change, University of Southampton

\begin{abstract}
The article presents an overview of trends in cohabitation and marriage in Britain over several decades, using a consistent set of retrospective histories from the General Household Survey 1979-2007. Time-trends are presented, for men and women, of: the experience of different types of partnership by specified ages, the frequency of premarital cohabitation, the average time spent in different types of partnership, the timing of life course transitions, and the outcome of cohabitation and marriage at the fifth and tenth anniversaries.
\end{abstract}




\section{Introduction}

We present in this article a statistical update on levels and trends in marriage and cohabitation in Britain in recent decades. Family change is one of the most prominent social trends of recent times in Britain as in other developed countries, including both Eastern and Southern Europe $e^{1,2,3,4,5,6,7}$. Among the most striking developments is the growth in prevalence of unmarried cohabitation. In the early 1960s in Britain fewer than one in a hundred adults under 50 are estimated to have been cohabiting at any one time ${ }^{8}$, compared with one in six currently. Cohabitation has become a normal part of the life course, though not yet, according to General Household Survey (GHS) figures, a majority experience for all adults. In 2004-07, 61 per cent of men aged 25-44 and 64 per cent of women of this age had cohabited at some point in their lives; of those aged 45-59, 38 per cent of men and 35 per cent of women, had done so. Attitudes appear to have adapted to this change in behaviour. Cohabitation is no longer seen as socially deviant: for example, two thirds of respondents to the 2006 British Social Attitudes survey thought that there was 'little difference socially between being married and living together as a couple'. On the other hand, the vast majority of the same sample clearly saw a distinction between them, as fewer than one in ten agreed that there was 'no point in getting married', that it was 'only a piece of paper'.

The distinction between cohabitation and marriage is of importance to policy makers too, as well as to social and political commentators ${ }^{10}$. Issues of policy interest include legal rights and responsibilities of cohabiting partners, the welfare of children of unmarried parents, concern about the stability of new family forms, housing demand, estimating the numbers of lone parent families, and population estimates and projections by marital status $8,11,12,13,14,15$. In addition, the links between policy environments and family behaviour are an active area of research ${ }^{16,17}$.

For all these reasons, good information on family trends of all kinds have much practical interest. But trends in cohabitation are, precisely because of its informal character, harder to document than changing patterns of marriage, as sources of information on cohabitation are much less complete. Developments in the level and timing of marriage can be identified in reasonable detail from vital registration statistics, whose particular strength is the long range historical perspective they can provide. Since cohabitation is, by definition, not a formally registered state, a statistical portrait of the subject cannot be drawn, except indirectly, from vital registration data ${ }^{18,19}$. Sample surveys are the primary alternative source but have two main drawbacks: long runs of consistent information are not usually available, and estimates of the frequency of cohabitation vary from one survey to another $^{8,20}$. The GHS has long been a key source on the subject ${ }^{21,22,23,24}$. Others include the Labour Force Survey (LFS) and Annual Population Surveys ${ }^{13,25}$, and several longitudinal studies $^{8,15,26,27,28,29}$.

The present article uses a consistent set of data from a time-series of the GHS from 1979-2007 to document changes in co-residential partnerships - marriage and cohabitation - in Britain over several decades. We use this data resource to document time-trends in the frequency of different types of partnership by age and sex, the duration and outcome of cohabiting and marital relationships, the timing of relationships, and the time spent in different types of relationship. 


\section{Data}

\section{Centre for Population Change GHS time series dataset}

As data sources are varied, and not always consistent with each other, it is particularly advantageous to have available a long time series of GHS rounds, in which retrospective histories of marriage and cohabitation have been collected. Our information on some features of people's partnership experience covers a longer time period than others, and questions asked in the GHS on marriage and cohabitation have varied over time. From 1979 onwards, a full marriage history was collected, including for some years up to seven marriages, together with information on whether respondents had cohabited prior to the marriage current at interview, and how long respondents cohabiting at interview had been doing so; from 1981 onwards the duration of premarital cohabitation before current or most recent marriage was collected, and before all marriages from 1989 onwards. From 2000, details were collected in addition of up to three spells of cohabitation that did not result in marriage to that partner ${ }^{30}$. It is, therefore, only from the GHS round of 2000 onwards that a near complete partnership history has been collected in the GHS. Depending on the topic, some analyses of time-trends in the present article are based on the entire GHS series from 1979-2007 and others are confined to the GHS rounds 2000-07. Because a longitudinal design was introduced into the GHS in 2005, three quarters of interviews in 2006 and 2007 are repeat interviews and are excluded from the present analyses.

Internal checks on the marriage and partnership histories in the Centre for Population Change (CPC) time series data set have found relatively little missing or incoherent data and only light editing was required. The retrospective cohabitation histories collected from 2000 onwards give a somewhat higher prevalence of cohabitation than the cross-sectional figures on cohabitation at survey in GHS rounds five and ten years previously, both overall and in specific age groups ${ }^{30}$. An evaluation of the marriage histories against cohort figures from vital registration gives good agreement in most cases. However, the data on marital separation in men's marital histories are inaccurate, giving a frequency that is too low and inconsistent with vital registration data on divorce. Figures presented below on marital separation are, therefore, confined to women.

\section{The GHS as a source on cohabitation}

An earlier analysis of GHS rounds 1993-95 found, as with the present more recent and more complete histories, slightly higher levels of cohabitation in retrospective cohabitation histories compared with cross-sectional reports of partnership status at preceding surveys back to 1960 , even though the 1993-95 information did not include spells of cohabitation that ended in separation $^{8}$. Cross-sectional GHS cohabitation figures for recent years agree well with those from the LFS, specific by marital status ${ }^{13}$, but in earlier years the prevalence of cohabitation was higher in the GHS than in the LFS, possibly due to the greater attention to recording family status in the GHS than in the LFS ${ }^{25}$. Estimates of premarital cohabitation from the GHS are somewhat above those obtained indirectly from marriage registration at younger ages, but otherwise in broad agreement with this source ${ }^{29,31}$. Nevertheless, estimates of the frequency of cohabitation based on the GHS are lower than in the Omnibus Survey and the British Household Panel Survey. The origin of these differences is hard to identify. Biases including differential non-response may well be involved, as well as definitional differences ${ }^{8,20}$. 


\section{Time span}

From 1979-85, demographic histories were collected from all women aged 18-49 and ever married women aged 16-17; from 1986, the information was obtained from all women aged 16 to 59 , and male marriage histories were also collected. In the years (1986 to 2007) when the Family Information section was administered to respondents aged up to 59, the retrospective histories allow us to document exposure and events at ages under 45 for the 15 years preceding the survey, experience at ages under 40 for the 20 years preceding the survey, and so on. In earlier rounds of the GHS (1979 to 1986), where the upper age limit for the Family Information section was lower, coverage of periods preceding the survey is correspondingly more restricted. Because both the information collected and the applicable age limits vary across GHS rounds, the time span over which the analyses are presented differs according to the topic under discussion.

\section{Weighting}

ONS survey weights are available for GHS rounds from 1996 onwards only. In view of sizeable non-response before then and of known biases in unweighted estimates of fertility parameters, we have computed two new sets of weights on a consistent basis for the entire series of GHS rounds 1979-2007. These are designed to adjust for household and individual non-response to the Family Information section and to calibrate to population distributions by age, sex and region ${ }^{32}$. One set is specific to households and the other to respondents to the Family Information section of the GHS questionnaire. As marriage and cohabitation histories are asked in the Family Information section of the GHS, all analyses in the present article are weighted using this second, individual, set of weights, in normalised form. Strictly, weighting will increase the variance of our estimates but, on the other hand, calibration to population totals would be expected to offset this to a large degree. The combined effect of these factors will, in any case, be less than that due to survey design, but as information on sample clustering is not present in the publicly available GHS data files, we are not in a position to adjust the estimated confidence intervals for this effect. We therefore estimate standard errors on the assumption of simple random sampling, and calculate confidence intervals as twice the standard error.

\section{Definitions}

Clarification of some terms may be useful. A direct marriage is one in which the bride and groom did not live together immediately before marriage. By premarital cohabitation, we mean a spell of cohabitation that ended with marriage to that partner; the marriage could be a first or a second or later marriage. The term cohabitation, unqualified, includes premarital cohabitation and spells of cohabitation that either ended in separation or were still current at interview. The terms partnership or relationship include both marriage and cohabitation. We present no data in this article on socalled 'living apart together' relationships in which the partners do not live together.

\section{Experience of partnership}

Changes in partnership over several decades are portrayed in Figure 1, which plots time trends by age and sex in the cumulative incidence of each type of partnership (see also Appendix Table A1). In the first panel, we graph the proportions of those aged 25-29 in each time period who had, by their 25th birthday, experienced each type of union; subsequent panels are constructed similarly (for example, experience of union types by the 30th birthday among those aged 30-34 in each period, and so on). 
Figure 1 Percentage ever having cohabited, married, or entered any union by specified exact ages, and by sex. Great Britain, GHS 2000-2004/07

by 25 th birthday

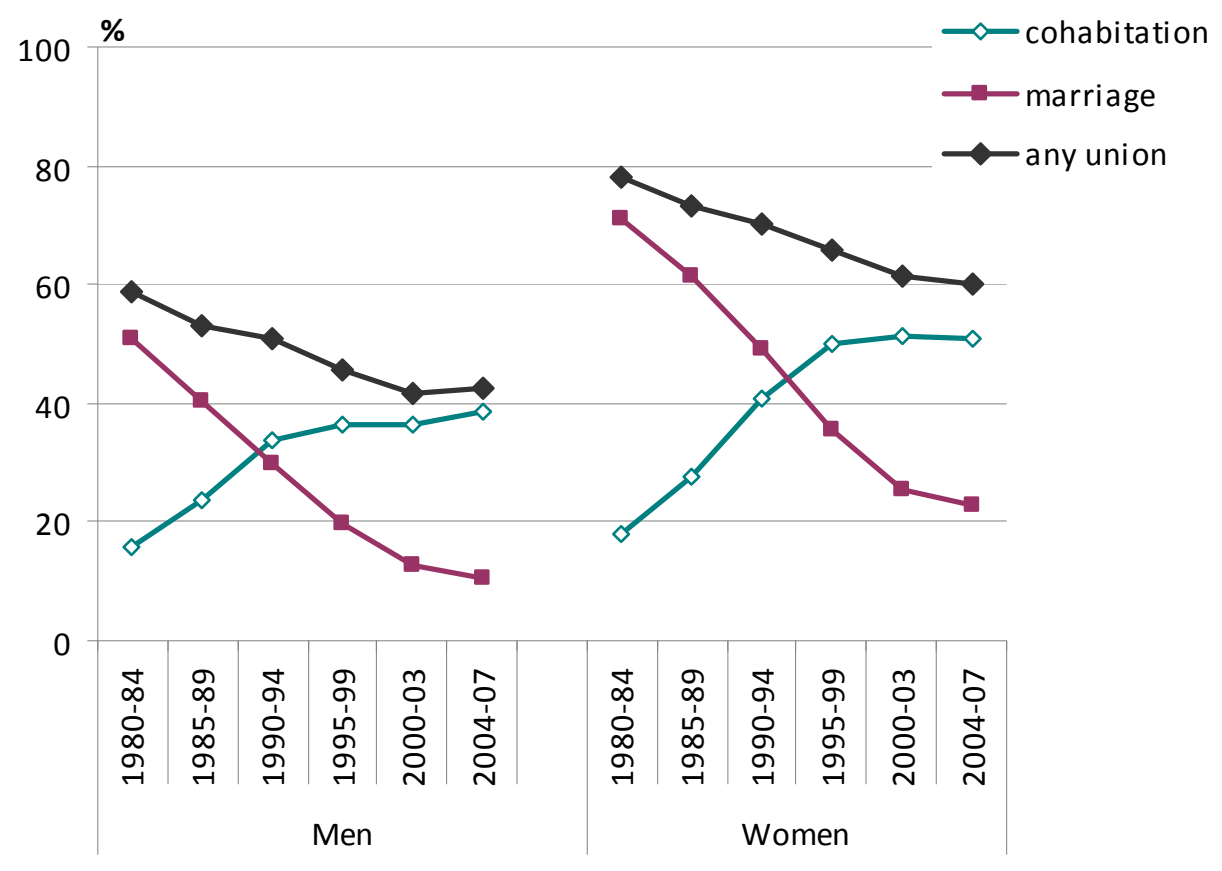

by 30 th birthday

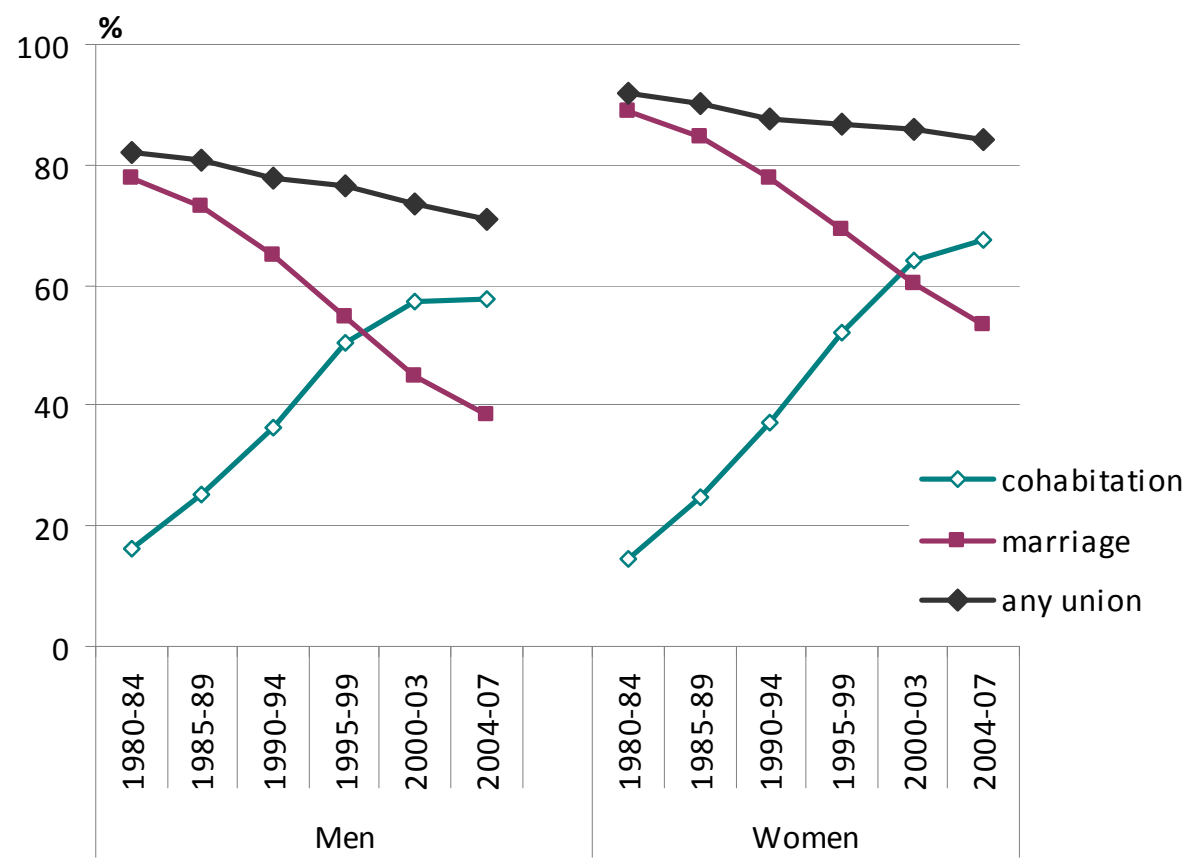


by 35 th birthday

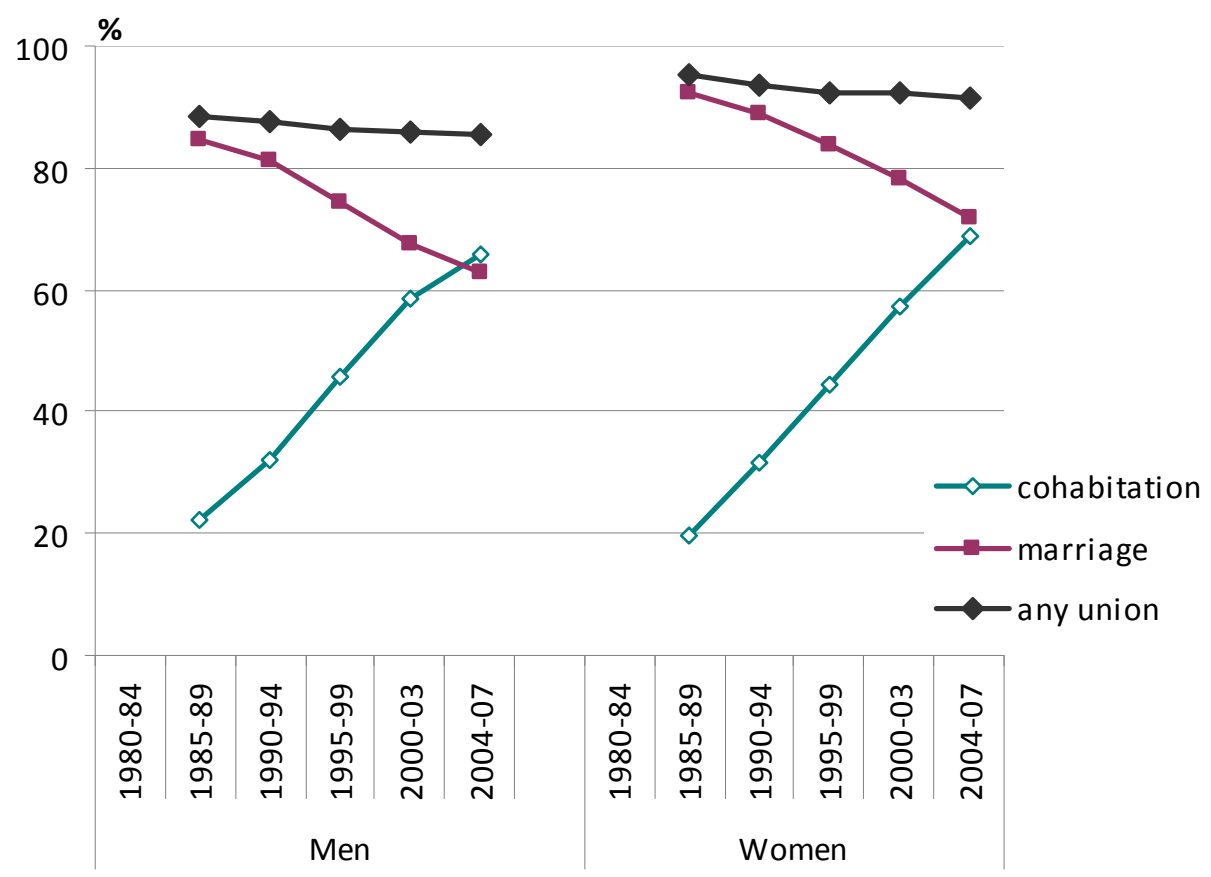

by 40 th birthday

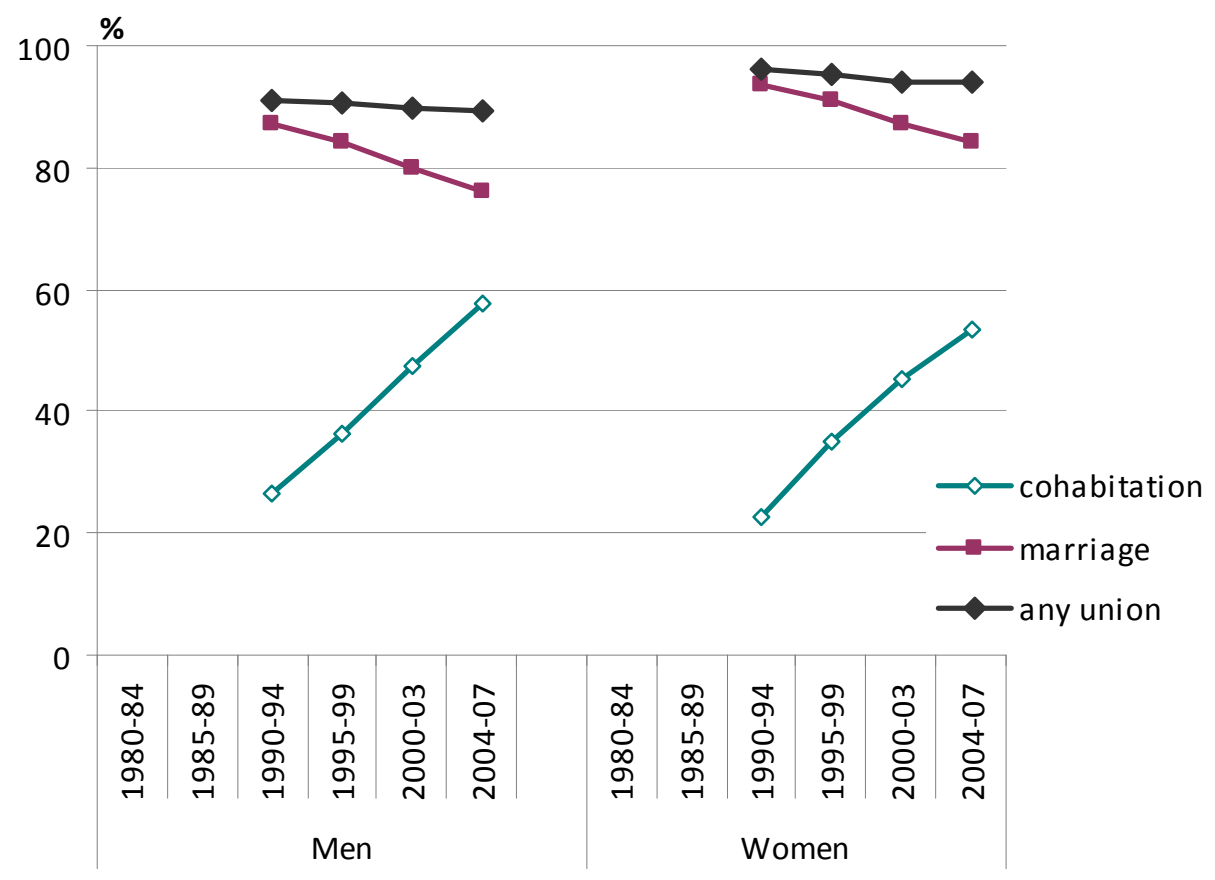

Note: For graphical clarity, confidence intervals around these percentages are not plotted but are given in Appendix Table A1, which summarises the data used in this figure.

Source: CPC GHS time series datafile 
Several aspects of recent trends in partnership emerge clearly in Figure 1. The result of several decades of decline in marriage rates is evident in the proportions ever having married by any specified age: at ages up to the late 30 s, progressively fewer have been married more recently than in the past. Nevertheless, while also true by age 40 the drop is less steep at older ages. This demonstrates that much of the downward trend at younger ages is due to delayed marriage, as we will see below. By contrast with marriage trends, the cumulative incidence of cohabitation to each age has been rising over time (though, as noted elsewhere ${ }^{13}$, the upward trend has been levelling off at younger ages, while continuing at older ages). These countervailing trends do not offset each other in younger age groups - the rise in cohabitation does not make up for the decline in marriage at younger ages. For example while 59 per cent of men aged 25-29 in 1980-84 had experienced at least one partnership by the age of 25 , this was true of just 43 per cent of the age group in 2004-07; among women of this age we see a decline from 78 per cent to 60 per cent over the same period. Nevertheless, at older ages, the drop in the experience of partnership is small, and so the rise in cohabitation largely compensates for the decline in marriage at these ages. Between 1985-89 and 2004-07 the proportion of 35-39 year old men having experienced at least one partnership by their 35th birthday fell just three percentage points, from 89 per cent to 86 per cent, and a relatively small decline occurred also among women, from 95 per cent to 91 per cent. The change from 1990-94 to 2004-07 in the experience of partnership by age 40 is narrower still: from 91 per cent to 89 per cent (men) and from 96 per cent to 94 per cent (women) ${ }^{33}$. While figures at older ages are available for shorter time periods, there is less change over comparable periods at older than at younger ages.

Putting the data from Figure 1 into historical perspective brings to the fore some aspects of recent partnership trends that can easily be overlooked. Although marriage rates have been in decline for decades, this is, from one perspective, statistically unremarkable, since marriage rates in the 1960 s and early 1970 s were at an all-time high ${ }^{34}$. So, although the 84 per cent of women ever married by their 40th birthday in 2004-07 represents a decline over recent decades, it is higher at this age than at any time in the first half of the 20th century, in England and Wales ${ }^{35}$. The proportion of men ever married by age 40 in the most recent period is, however, the lowest it has been in the last century and a half. Nevertheless, there has been no flight from partnership per se. We saw that around 89-91 per cent of men and 94-96 per cent of women reaching 40 in the last 20 years have been in at least one partnership, whether cohabitation or marriage. These figures are, for both sexes, around the maximum proportions who ever experienced a marriage among the record-setting generations of the 20th century: men born in the 1930s-40s, 91 per cent of whom ultimately married, and women born in the 1940s, of whom 95 per cent ultimately married. In other words, the cumulative incidence of some form of partnership among men and women reaching their 40 s recently is about the same as the cumulative incidence of marriage among the most married generations of the twentieth century: men reaching their 40s in the 1970s and women reaching their 40s in the 1980s. There has, thus, been no retreat from partnership in principle, though, as can be inferred from Figure 1, life in a couple now starts at later ages than in the recent past, and relationships do not last as long as formerly, as we will see below.

There can be no doubt, however, that the decline in marriage at younger ages has been dramatic. For example, the proportions of men and women in recent years ever married by age 25 are the lowest on record over the last 100 years. But, again, if we count either cohabitation or marriage by 25 we find a cumulative experience of partnership by the 25th birthday in 2004-07 that is 
comparable to the proportions ever married by that age obtaining between the 1920 s and the early 1940s in England and Wales.

\section{The link between cohabitation and marriage}

Much is written on whether cohabitation is a marriage-like relationship, a substitute for marriage or an alternative to the single state ${ }^{36}$. Regardless of how we view the two types of relationship, the statistical links between them are, on the one hand, close, and, on the other, changing through time.

Table $1 \quad$ Percentage of marriages preceded by premarital cohabitation, by age at and year of marriage, and sex. Great Britain, GHS 1979-2007

\begin{tabular}{|c|c|c|c|c|c|}
\hline \multirow[b]{2}{*}{ Year of marriage } & \multicolumn{5}{|c|}{ Age at marriage } \\
\hline & $16-24$ & $25-29$ & $30-39$ & $40-49$ & All ages \\
\hline \multicolumn{6}{|l|}{ Men } \\
\hline $1960-64$ & $2.2(0.5)$ & $4.6(1.2)$ & & & \\
\hline $1965-69$ & $4.0(0.5)$ & $6.1(1.1)$ & & & \\
\hline 1970-74 & $10.5(0.8)$ & $15.2(1.4)$ & $27.8(3.1)$ & & \\
\hline 1975-79 & $17.2(1.1)$ & $26.6(1.7)$ & $43.2(2.6)$ & & \\
\hline 1980-84 & $27.8(1.4)$ & $39.1(1.8)$ & $57.7(2.2)$ & $59.7(5.0)$ & $38.8(1.0)$ \\
\hline 1985-89 & $43.6(1.7)$ & $51.3(1.7)$ & $63.0(2.0)$ & $67.2(3.5)$ & $52.5(1.0)$ \\
\hline 1990-94 & $53.7(2.6)$ & $66.3(1.9)$ & $74.1(2.0)$ & $75.2(3.2)$ & $66.6(1.2)$ \\
\hline 1995-99 & $53.4(4.6)$ & $73.2(2.5)$ & $78.7(2.0)$ & $78.6(3.7)$ & $73.7(1.4)$ \\
\hline 2000-03 & $53.8(7.2)$ & $70.7(3.9)$ & $80.2(2.8)$ & $82.5(4.5)$ & $74.9(2.0)$ \\
\hline 2004-07 & 65.8 (19.4) & $72.7(9.6)$ & $81.6(6.4)$ & 81.9 (10.7) & $78.0(4.7)$ \\
\hline \multicolumn{6}{|l|}{ Women } \\
\hline $1960-64$ & $2.4(0.4)$ & $7.7(2.0)$ & & & \\
\hline $1965-69$ & $3.7(0.4)$ & $10.6(2.0)$ & & & \\
\hline 1970-74 & $9.0(0.6)$ & $22.4(1.9)$ & $34.6(3.9)$ & & \\
\hline 1975-79 & $17.2(0.9)$ & $36.8(2.1)$ & $47.9(2.9)$ & & \\
\hline 1980-84 & $28.2(1.1)$ & $50.5(2.1)$ & $63.2(2.4)$ & $59.8(5.2)$ & $38.4(0.9)$ \\
\hline $1985-89$ & $43.4(1.3)$ & 59.9 (1.8) & $67.0(2.1)$ & $67.0(3.8)$ & $52.9(0.9)$ \\
\hline 1990-94 & $55.8(1.8)$ & $71.3(1.8)$ & $76.2(2.0)$ & 72.9 (3.5) & $66.6(1.1)$ \\
\hline 1995-99 & $58.2(3.0)$ & $77.1(2.1)$ & $80.4(2.1)$ & $77.9(4.0)$ & $73.5(1.3)$ \\
\hline 2000-03 & $53.6(4.8)$ & 76.9 (3.3) & $85.2(2.6)$ & $77.8(5.4)$ & $74.8(1.9)$ \\
\hline 2004-07 & $68.4(12.4)$ & $78.0(8.5)$ & $86.7(5.8)$ & $86.3(10.1)$ & $80.7(4.3)$ \\
\hline
\end{tabular}

Note: $2 \mathrm{x}$ standard error is given in parentheses

Source: CPC GHS time series data file

Table 1 shows the trend in the proportions cohabiting premaritally from 1960-64 to the present. In the 1960s, living with a prospective marital partner before marriage was relatively rare, with just three per cent of those marrying at ages below 30 doing so. By the 1970s a quarter of men and women marrying at ages under 50 cohabited with their partner prior to marriage. According to GHS figures, it is since the late 1980s that more than half of all couples marrying have lived together beforehand, and so premarital cohabitation has been a majority practice for a quarter of a century. In recent years, the vast majority of people marrying at ages under 50 - close to four in five - have 
lived together prior to marriage. Indeed, marriage without first living together is now as unusual as premarital cohabitation was in the 1970s.

Table 2 Cohabitation before first marriage 1980-84 to 2004-07. Men and women aged $<60$. Great Britain, GHS 2000-2007

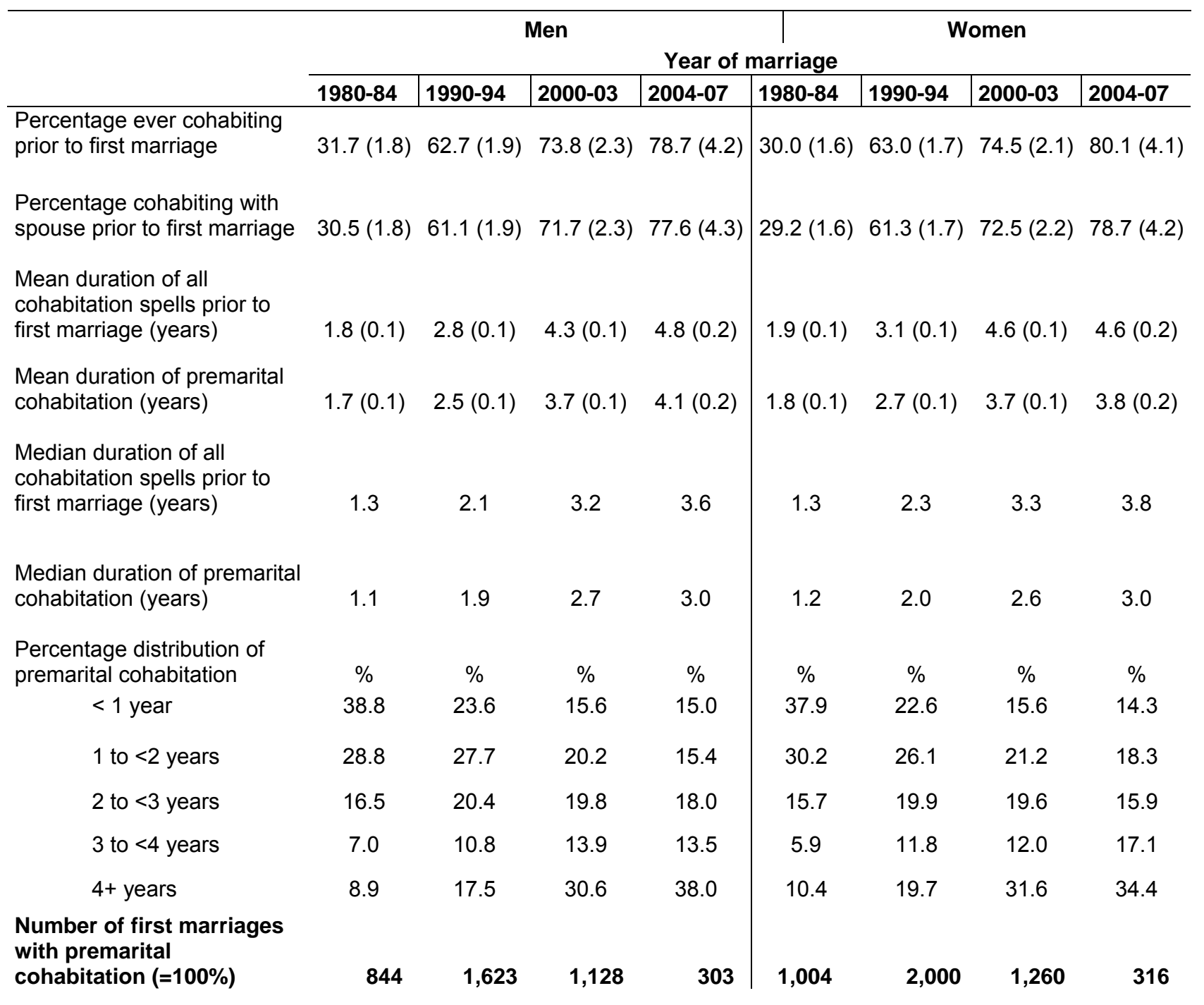

Note: $2 \mathrm{x}$ standard error is given in parentheses

Source: CPC GHS time series data file

Premarital cohabitation is more common among those who marry at older ages. But although marriage has been increasingly delayed in recent decades, later marriage age does not explain the rise in premarital cohabitation: we see in Table 1 that the frequency of premarital cohabitation has been rising at all marriage ages.

The data in Table 1 are for all marriages, whether first or later. Table 2 presents some information relating to the time before first marriage, and there we see that the upward trend in premarital cohabitation applies to first marriages also. Around eight in ten of those marrying for the first time in 2004-07 lived together beforehand, up from three in ten in 1980-84. Living with a partner before first marriage has been a majority practice since the early 1990s. Couples have, furthermore, been 
living together for longer. Premarital cohabiters who married for the first time in 2004-07 had lived together for four years on average (men: 4.1; women: 3.8), over twice as long as their counterparts in the early 1980s (men: 1.7; women: 1.8). While most married couples who lived together in the early 1980s did so for less than two years, in 2004-07 over half had lived together for three years or more. The frequency of premarital unions of 4+ years rose particularly sharply to reach 34-38 per cent of all such spells. Counting all partnerships, whether with their future spouse or with another partner, the total time cohabiters live together before first marriage now averages nearly five years (men: 4.8; women: 4.6). Multiple partnerships before first marriage, though not that common, have been growing in frequency. Of men and women marrying for the first time, 97 per cent (men) and 98 per cent (women) in 1980-84 had never lived with any other partner, against 81 per cent (men) and 84 per cent (women) in 2004-07.

\section{Timing}

We saw earlier a much sharper decline in the experience of marriage and partnership by age 25 than by age 40 . The lesser change at older ages is because much of what has been happening is that marriage and partnership have been increasingly delayed rather than foregone altogether. We can infer from Figure 1 that men and women reaching their 40s in recent years had to a large extent caught up with previous generations. Explicit evidence of delay is shown in Figure 2, which plots the mean age at first union that is a cohabitation, at first partnership, at first marriage, and at first birth (women), for the periods 1980-84 to 2004-07. The estimates are for events occurring by the 40 th birthday and the mean ages are standardised for age structure ${ }^{37}$.

We see in Figure 2 the move over several decades to a later timetable of life course events, among both men and women. The trends shown here have some noteworthy features. Several of these events - first partnership if a cohabitation, any first partnership, first birth - are in 2004-07 delayed by comparison with 1980-84 to approximately the same extent. In the most recent period, men are 1.5-1.8 years older, on average, and women are 1.9-2.2 years older at each of these transitions than in the early 1980s. Major life-course transitions have, thus, moved about two years up the age range in the last quarter of a century. Marriage, however, has been subject to much more substantial delay, with both men and women marrying for the first time an average of five years later in recent years than in the early 1980s. The reason for this additional delay is twofold. It arises both because the proportion of men and women who cohabit before their first marriage, either with their future spouse or with another partner, rose substantially over the past several decades, as we saw earlier, and because the time spent cohabiting lengthened. From Table 2 and Figure 2 we can say that the five-year delay in first marriage in 2004-07 by comparison to 1980-84 can be broken down approximately as follows: two years is due to a later start to the first partnership and three to the longer time spent cohabiting before first marriage.

Finally, we see that first marriage is now later on average than first birth - by about a year, in the most recent period. The reason is, of course, the growth in births outside marriage, with the proportion of all births that are non-marital, at over 40 per cent since 2000 , being two and a half times the proportion (16 per cent) in the early 1980s (England and Wales figures) ${ }^{38}$. Most of that growth is due to births to cohabiting couples. Just under three in ten women having their first birth in 2000-07 were cohabiting, nearly five times the figure of six per cent in 1980-84 (GHS estimates). The upward trend in this respect in Britain is shared with much of the rest of the developed world, though the frequency varies cross-nationally ${ }^{39}$. 


\section{Figure 2 Period estimates of mean age at several life course events: first cohabitation, first marriage, first partnership and first birth, by age 40 . GB, 1980-84 to 2004-07.}

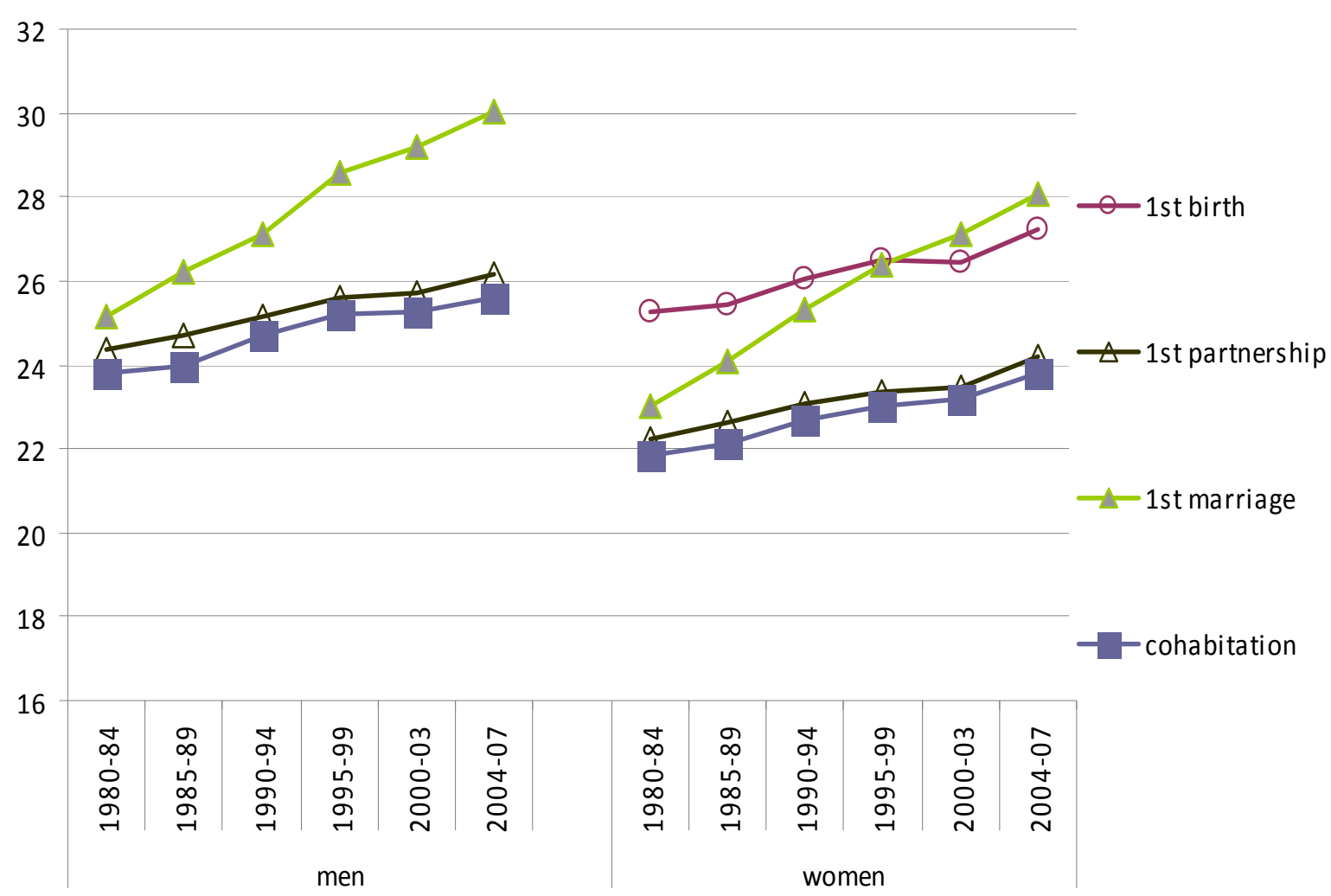

Notes: 1st partnership: first union, whether cohabitation or marriage.

The cohabitation figures refer to cohabitations that are the first union in a person's history, and do not include the first time a person cohabited if this occurred subsequent to first marriage.

Source: CPC GHS time series data file

\section{What becomes of cohabiting unions?}

We saw in an earlier section that, looking backwards from marriage, the large majority of couples marrying live together beforehand, and have been cohabiting for much longer than in the past. However, this does not mean that cohabitation inevitably leads to marriage. In Figure $\mathbf{3}$ and Table 3 we look forward from the start of cohabiting unions, and show what has been happening to these in the short and medium run, and how the outcomes have been changing. 
Figure 3 Percentage of cohabiting partnerships that end in (a) marriage and (b) separation, by year the cohabitation started. Men and women aged $<45$ at the start of cohabiting union. Great Britain, GHS 2000-2007

\section{A Marriage}

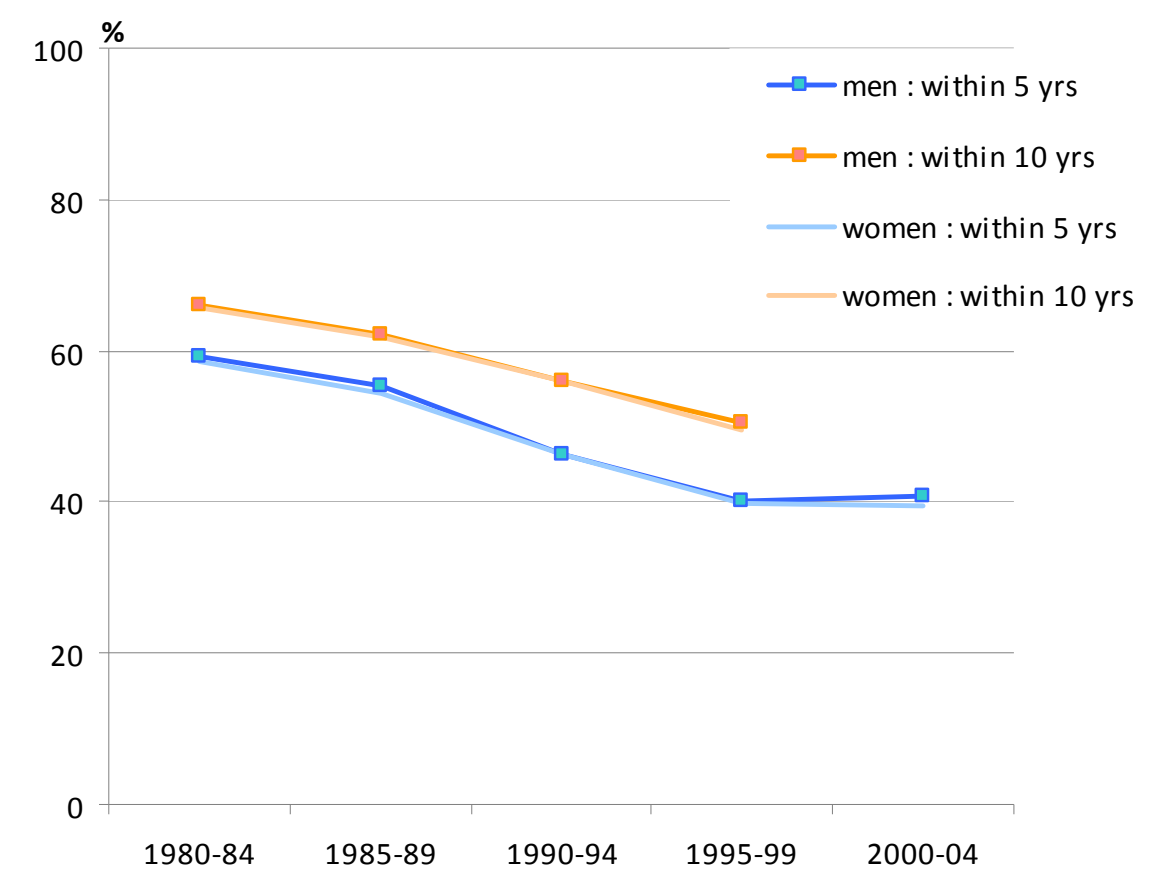

\section{B Separation}

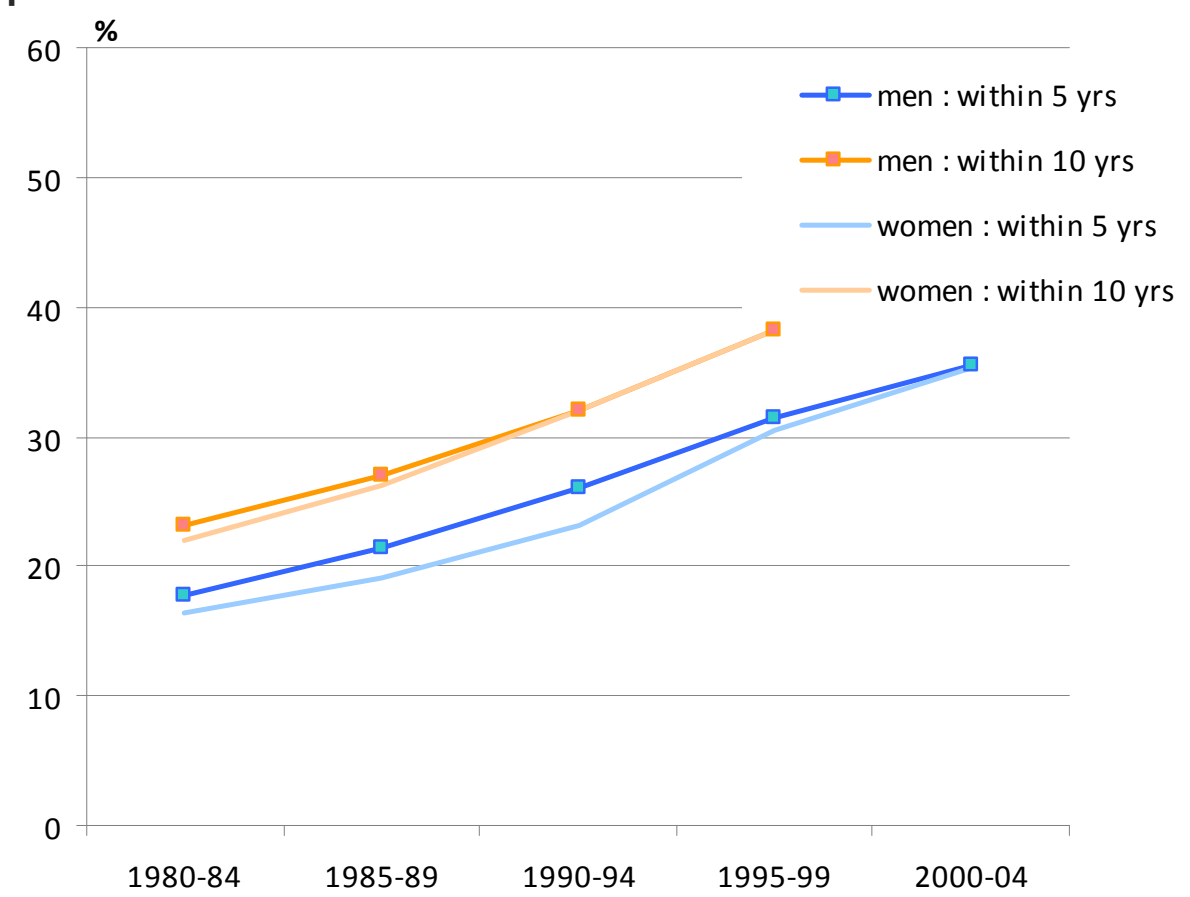

Source: CPC GHS time series datafile; see also note to Table 3

We saw in Figure 1 above that the proportion who cohabited by a given age has been rising. But over time, progressively fewer of those who live together ultimately marry, and a larger proportion 
separate. Just under three fifths of men and women under 45 who started cohabiting in 1980-84 had married within five years and the figure had fallen to just under two fifths in the most recent period (Figure $3 \mathrm{~A})^{40}$. By the tenth anniversary, two thirds of couples who moved in together in 1980-84 had married, against about a half in recent years. The propensity to marry has fallen because, in a purely numerical sense, the frequency of separation among cohabiters has been rising (Figure 3B and Table 3). Among couples who began cohabiting in 1980-84, one in six had separated (without marrying) within five years, a figure that had doubled, reaching one in three, by 2000-2004. These trends have offset each other to a large extent, with the net result that the proportion of cohabiters who are still living together unmarried five or ten years later has been fairly stable: in the range 23-30 per cent at the fifth anniversary and between 10 per cent and 12 per cent at the tenth anniversary. Thus, relatively few cohabiting couples are still living together unmarried after ten years ${ }^{41,42}$. In this sense, cohabitation is not a long-term arrangement for many couples in Britain. Nevertheless, overall, the majority of those starting a cohabitation, as in the past, are either still cohabiting or have married five or ten years later. But the size of that majority has been in decline: at the fifth anniversary from 82-84 per cent among those who started cohabiting in 1980-84 to 64-65 per cent in 2000-2004, and at the tenth anniversary from 77-78 per cent (1980-84) to 62 per cent (1995-99). At the same time, the duration of cohabiting spells has lengthened over time, from a median of just over two years in the early 1980 s to nearly three years in the most recent period.

\section{Table 3 Outcome of cohabiting relationships after 5 and 10 years, by sex and year the couple started cohabiting. Men and women aged under 45 at the start of the cohabiting union. Great Britain, GHS 2000-2007}

\begin{tabular}{|c|c|c|c|c|c|c|c|c|c|c|}
\hline & \multicolumn{5}{|c|}{ Men } & \multicolumn{5}{|c|}{ Women } \\
\hline & 1980-84 & $1985-89$ & 1990-94 & 1995-99 & 2000-04 & 1980-84 & 1985-89 & 1990-94 & 1995-99 & 2000-04 \\
\hline \multicolumn{11}{|l|}{5 years } \\
\hline Marriage & 59.3 & 55.4 & 46.2 & 40.0 & 40.8 & 58.6 & 54.3 & 46.3 & 39.9 & 39.5 \\
\hline Separation & 17.7 & 21.5 & 26.0 & 31.4 & 35.5 & 16.3 & 19.2 & 23.2 & 30.5 & 35.4 \\
\hline cohabitation & 23.0 & 23.1 & 27.8 & 28.5 & 23.7 & 25.1 & 26.5 & 30.5 & 29.6 & 25.2 \\
\hline \multicolumn{11}{|l|}{10 years } \\
\hline Marriage & 66.0 & 62.2 & 55.9 & 50.5 & & 65.9 & 61.9 & 56.1 & 49.4 & \\
\hline $\begin{array}{l}\text { Separation } \\
\text { Continuing }\end{array}$ & 23.2 & 26.9 & 32.0 & 38.2 & & 22.1 & 26.2 & 32.0 & 38.1 & \\
\hline cohabitation & 10.7 & 10.9 & 12.1 & 11.3 & & 12.1 & 11.9 & 12.0 & 12.4 & \\
\hline Sample numbers & 2,106 & 3,249 & 3,958 & 4,399 & 2,669 & 2,511 & 4,113 & 4,830 & 5,271 & 3,098 \\
\hline
\end{tabular}

Note: The estimates are from a competing risks life table and refer to how the cohabiting relationship ended, rather than to couples' situation 5 and 10 years later; thus cohabiters who married and subsequently separated are classified among marriages and not among separations.

Source: CPC GHS time series data file 


\section{Marital disruption}

Although cohabiting unions have become more unstable over time, this has not been true of marriages in the last two decades, at least at relatively early durations. Previous authors have noted, on the basis of vital registration statistics, that divorce rates have stabilised since the late $1980 \mathrm{~s}^{43}$. Table 4 shows that both separation and divorce by the fifth anniversary of marriage have declined somewhat since the early 1990s. The separation figures are based on the retrospective GHS partnership histories, and the proportions divorcing on vital registration statistics for England and Wales $^{44}$. We make no attempt here to investigate the reasons for the stabilisation and apparent decline in separation and divorce rates at shorter durations of marriage; that would require more detailed analysis than is possible in the present survey of trends. Several possibilities can, however, be mentioned. One potential reason is the long-run trend to later marriage - we saw in Figure 2 above that in recent years men and women have been marrying on average five years later than a quarter of a century ago. It has long been known that those marrying at older ages have a lower risk of marital breakdown ${ }^{43}$ and so later age may be part of the explanation for the cessation of the rise and the decline in marital disruption that is emerging at short durations. However, this is not the only explanation, in that vital registration statistics show that compared with people marrying in 1996, fewer of those marrying in 2000 had divorced by the fifth anniversary, at nearly all ages at marriage under 50; in some cases, the decline dates from 1991 marriages ${ }^{45}$.

Table 4 Percentage of women marrying at ages under 45 who separated $^{*^{1}}$ and divorced ${ }^{*^{2}}$ within 5 years, by year of marriage.

\begin{tabular}{l|c|c|c|c|c|}
\hline & \multicolumn{5}{|c|}{ Year of marriage } \\
\cline { 2 - 6 } & $\begin{array}{c}1980-84 \\
\%\end{array}$ & $\begin{array}{c}1985-89 \\
\%\end{array}$ & $\begin{array}{c}1990-94 \\
\%\end{array}$ & $\begin{array}{c}1995-99 \\
\%\end{array}$ & $\begin{array}{c}2000-04 \\
\%\end{array}$ \\
\hline Outcome at: & & & & & \\
5th anniversary & 13.8 & 15.1 & 15.3 & 14.4 & 12.1 \\
Separation (GHS) & 9.3 & 10.7 & 11.1 & 10.4 & 9.6 \\
Divorce (vital registration) & & & & & \\
10th anniversary & 25.6 & 26.1 & 27.0 & & \\
Separation (GHS) & 21.5 & 23.5 & 24.1 & 23.9 & \\
Divorce (vital registration) & & & & & \\
& $\mathbf{1 0 , 7 6 4}$ & $\mathbf{1 0 , 9 2 4}$ & $\mathbf{7 , 4 8 5}$ & $\mathbf{4 , 1 0 2}$ & $\mathbf{2 , 1 6 5}$ \\
\hline
\end{tabular}

Notes: $\quad{ }^{1}$ Separation: life table estimates; GB, GHS 1980-2005/7.

${ }^{2}$ Divorces: Vital registration statistics, England and Wales.

Source: CPC GHS time series data file

The advent of widespread cohabitation may be a further, and related, contributory factor. We have seen that over time premarital cohabitation has become more common (Table 1), that couples live together for longer periods before first marriage (Table 2), and that proportionately fewer cohabiters marry, and more separate without marrying, by any given time after they start living together than in the past (Figure 3 and Table 3). As a result, relationships may be subject to 
greater testing before marriage than in the recent past, with cohabitation screening out weaker partnerships $46,47,48,49$. If this is indeed what is happening, those marrying may be increasingly select as to the likely future stability of their relationship. In that sense, the spread of cohabitation may be a contributory cause of the recent stabilisation of marriage, and of the incipient decline in rates of marital disruption.

\section{Time spent in partnerships}

One way of encapsulating the consequences of recent changes in the level and timing of partnership in Britain is to look at changes in the total time spent in specific statuses. This is done in Table 5, which shows the mean number of years spent, by the 40th birthday, in any kind of partnership, or in a marriage, by men and women aged 40-44 in 1990-94 to 2004-07. Overall, both men and women in their early 40s in recent years have spent 1.5-1.7 fewer years in a partnership than their counterparts in the early 1990s. This relatively small change is the product of a later age at entry into partnership, and a slight decline in the proportions ever having been in a relationship by age 40 over that period, and also to higher levels of separation. Time spent married, however, has declined by a larger margin: 3.6-3.7 fewer years married, on average, than 15-20 years ago. Most of this is due to later marriage age, and to time between marriages: a decline of 2.5 for men and 2.3 for women; the remainder - men 1.2, and women 1.3 - is attributable to lower levels of marriage.

\section{Table $5 \quad$ Mean time spent in any partnership or in marriage by age 40. Men and women aged 40-44, 1990-2007. Great Britain, GHS 2000-2007}

\begin{tabular}{|l|c|c|c|c|}
\hline & \multicolumn{2}{|c|}{ Mean no. of years in partnership } & \multicolumn{2}{c|}{ Mean no. of years married } \\
\cline { 2 - 5 } & All & $\begin{array}{c}\text { Among those ever in a } \\
\text { union }\end{array}$ & All & $\begin{array}{c}\text { Among those ever } \\
\text { married }\end{array}$ \\
\hline Men & 13.4 & 14.7 & 13.1 & 15.0 \\
$1990-94$ & 13.1 & 14.4 & 12.2 & 14.4 \\
$1995-99$ & 12.3 & 13.7 & 10.7 & 13.4 \\
$2000-03$ & 11.9 & 13.3 & 9.4 & 12.4 \\
$2004-07$ & -1.5 & -1.4 & -3.7 & -2.5 \\
change 1990-4 to 2004-07 & & & & \\
Women & & & & \\
1990-94 & 15.9 & 16.6 & 15.8 & 16.9 \\
1995-99 & 15.5 & 16.3 & 14.9 & 16.3 \\
$2000-03$ & 14.7 & 15.6 & 13.3 & 15.3 \\
$2004-07$ & 14.3 & 15.1 & 12.3 & 14.6 \\
change 1990-4 to 2004-07 & -1.7 & -1.4 & -3.6 & -2.3 \\
\hline
\end{tabular}

Source: CPC GHS time series data file

\section{Partnership status and history in 2004-07}

A further summary of the net outcome of recent trends is given by figures on the cumulative partnership experience of men and women by age in the most recent period. The proportion of men and women who had ever married, ever cohabited, and ever experienced one or other of these kinds of partnership, is shown by age group in Table 6, for 2004-07. Consistent with the 
delay in lifecourse transitions, we see that only a minority of those aged under 25 had ever been in a union. The absence of a large-scale rejection of partnership on the other hand is evident from the large majority of those aged 25 and above who had been in some type of union - cohabitation or marriage - at some time in their lives. Most men and women aged 25-44 had cohabited at some point in the past. The oldest age group considered here - those 45-59 in 2004-07 - had less experience of cohabitation than did 25-44 year olds; nevertheless, over a third had lived in an unmarried relationship at some point.

There is a sizeable gap in all but the youngest age groups between the proportions ever in a partnership and those in a partnership at the time of the survey, as seen in Figure 4. The disparity is due at these ages primarily to relationship breakdown, though at older ages widow(er)hood is also a contributory factor. From Table 6 we see that over three in ten men, and nearly four in ten women aged 35-59 had been separated from at least one cohabiting or married partner. Over seven in ten separated men and two thirds of separated women of these ages had found a further partner. A fifth of men and women aged 35-59 were living with a second or later partner at the time of the survey.

\section{Table 6 Percentage ever in each type of union, ever separated and repartnered, and current union status at survey, by age group and sex. Men and women aged 18-59. Great Britain, GHS 2004-2007}

\begin{tabular}{|c|c|c|c|c|c|}
\hline & \multicolumn{5}{|c|}{ Age at survey } \\
\hline & $\begin{array}{c}18-24 \\
\%\end{array}$ & $\begin{array}{c}25-34 \\
\%\end{array}$ & $\begin{array}{c}35-44 \\
\%\end{array}$ & $\begin{array}{c}45-59 \\
\%\end{array}$ & $\begin{array}{c}\text { All ages } \\
\%\end{array}$ \\
\hline \multicolumn{6}{|l|}{ Men } \\
\hline Ever cohabited & $17.2(1.9)$ & $58.7(1.9)$ & $62.8(1.6)$ & $38.1(1.4)$ & $46.5(0.9)$ \\
\hline Ever married & $2.6(0.8)$ & $36.1(1.8)$ & $73.0(1.5)$ & $87.3(0.9)$ & $58.4(0.9)$ \\
\hline Ever in union & $18.2(2.0)$ & $70.5(1.7)$ & $89.4(1.1)$ & $92.3(0.8)$ & $74.8(0.8)$ \\
\hline Ever separated & $6.3(1.2)$ & $21.6(1.6)$ & $34.4(1.6)$ & $31.9(1.6)$ & $26.2(0.9)$ \\
\hline Of ever separated, \% ever repartnered & $26.0(8.5)$ & $61.5(3.9)$ & $74.0(2.5)$ & $75.2(4.2)$ & $70.3(2.8)$ \\
\hline Cohabiting at survey & $10.7(1.6)$ & $25.0(1.6)$ & $14.2(1.4)$ & $6.6(1.0)$ & $13.6(0.6)$ \\
\hline Married at survey & $2.4(0.8)$ & $33.3(1.8)$ & $61.1(1.6)$ & $72.8(1.4)$ & $49.5(0.9)$ \\
\hline In union at survey & $13.1(1.7)$ & $58.3(1.8)$ & $75.2(1.6)$ & $79.3(1.2)$ & $63.2(0.8)$ \\
\hline In second or later union at survey & $1.1(0.5)$ & $9.8(1.1)$ & $20.8(1.4)$ & $19.5(1.3)$ & $14.7(0.7)$ \\
\hline \multicolumn{6}{|l|}{ Women } \\
\hline Ever cohabited & $32.3(2.1)$ & $65.4(1.6)$ & $62.8(1.5)$ & $34.7(1.3)$ & $49.1(0.8)$ \\
\hline Ever married & $8.2(1.3)$ & $50.5(1.7)$ & $80.0(1.2)$ & $92.7(0.7)$ & $66.2(0.8)$ \\
\hline Ever in union & $36.1(2.2)$ & $82.1(1.3)$ & $93.6(0.8)$ & $96.3(0.5)$ & $82.7(0.6)$ \\
\hline Ever separated & $11.5(1.5)$ & $29.4(1.6)$ & $39.5(1.5)$ & $37.6(1.6)$ & $32.1(0.9)$ \\
\hline Of ever separated, \% ever repartnered & $30.2(5.6)$ & $59.4(3.0)$ & $68.0(2.2)$ & $65.2(3.4)$ & $62.9(2.2)$ \\
\hline Cohabiting at survey & $19.8(1.8)$ & $22.7(1.4)$ & $12.3(1.3)$ & $5.7(0.9)$ & $13.6(0.5)$ \\
\hline Married at survey & $7.4(1.2)$ & $44.5(1.7)$ & $62.8(1.5)$ & $71.8(1.3)$ & $52.9(0.8)$ \\
\hline In union at survey & $27.2(2.0)$ & $67.2(1.6)$ & $75.1(1.4)$ & $77.4(1.2)$ & $66.6(0.7)$ \\
\hline In second or later union at survey & $2.4(0.7)$ & $14.4(1.2)$ & $21.4(1.3)$ & $19.1(1.2)$ & $16.0(0.6)$ \\
\hline
\end{tabular}

Note: $2 \mathrm{x}$ standard error is given in parentheses

Source: CPC GHS time series datafile 
In all age groups many fewer are cohabiting at the time of the survey than have ever cohabited. This is a further reflection of the relatively short duration of cohabiting relationships, as we saw above. At ages 35 and above, more people have been married than have ever cohabited, but the opposite is true of those under 35. Differences between age groups in Table 6 reflect in part the effect of age itself, with those at older ages having had more cumulative experience of partnership in general. However, they also reflect the substantial changes in partnership that have been taking place since the 1970s.

\section{Figure 4 Percentage who had ever been in a partnership, and who were in a partnership at the time of the survey, by age and sex, 2004-07. Men and women aged 18-59. Great Britain, GHS 2004-07}

Men

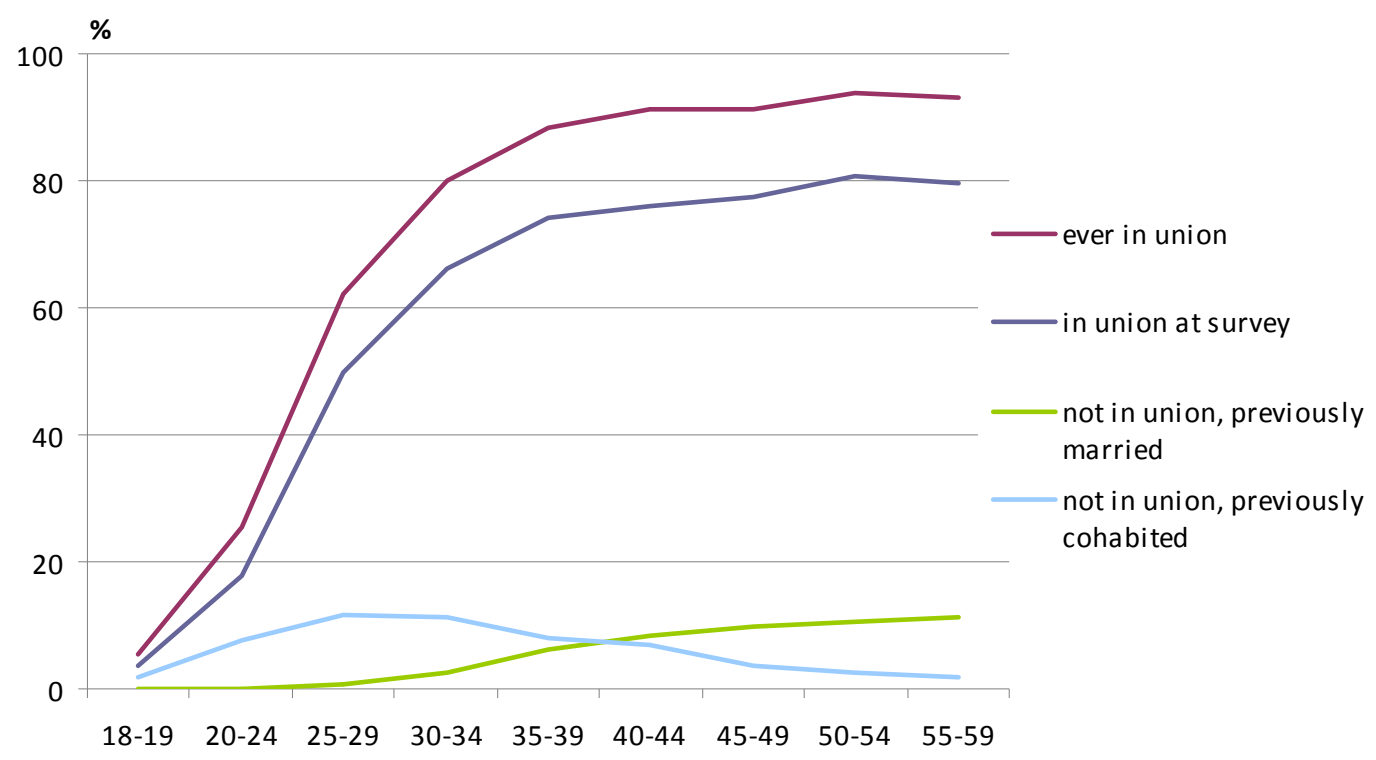

\section{Women}

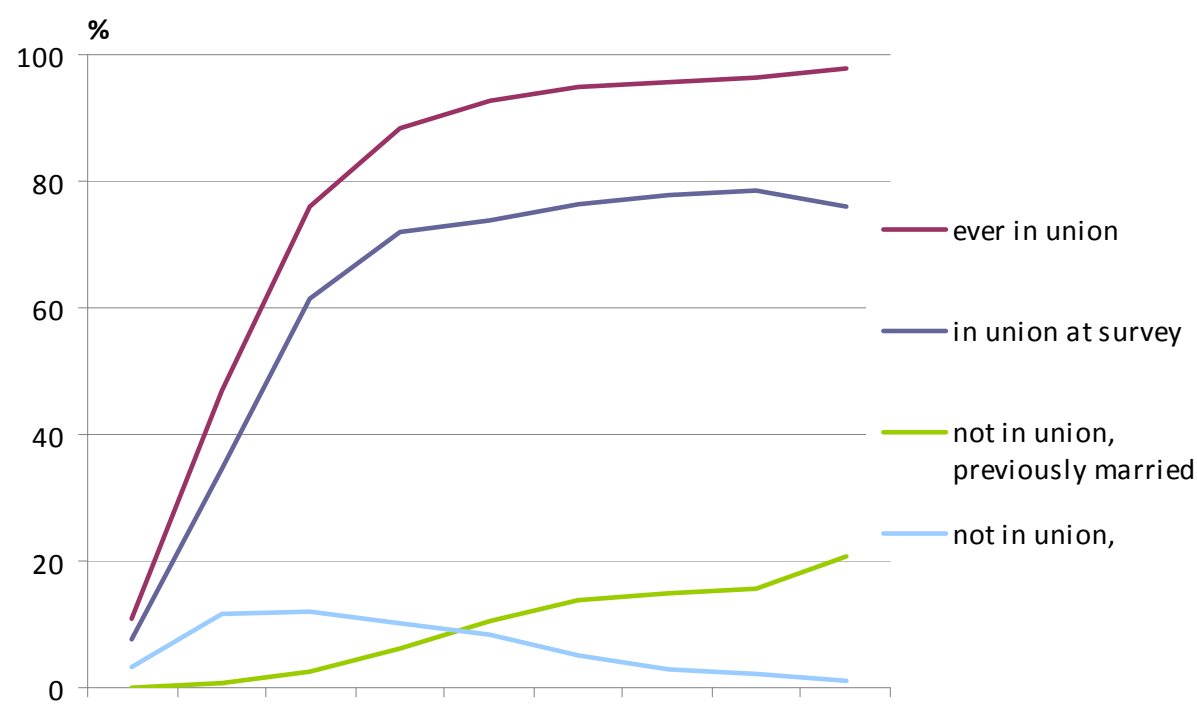

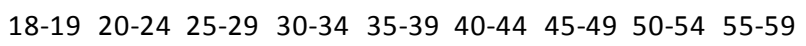

Note: People not in union who had previously been both married and in a cohabiting union are classified as 'not in union, previously married'.

Source: CPC GHS time series datafile 


\section{Discussion}

Partnership behaviour has been in continuous change in Britain for over three decades.

Cohabitation is continuing to grow, and the large majority of people aged 25-44 currently have cohabited at some time in their lives. The vast majority of marriages - 80 per cent in recent years are now preceded by a spell of cohabitation. The growth in cohabitation does not compensate for the decline in marriage at younger ages, but among those in their early 40s, in recent years, it comes close. Putting recent trends in historical context, if we consider both cohabitation and marriage together, the frequency of entering a partnership among people reaching their 40s currently is on a par with the frequency of marriage in the most married generations of the 20th century. That is, both men and women have been entering some form of co-residential relationship, marriage or cohabitation, at about the maximum level reached by its traditional form, marriage, during the 20th century in Britain (the vital registration comparison is with England and Wales). In that sense, there has been no retreat from partnership per se. Partnership trends in recent decades are certainly distinctive, but are not entirely discontinuous with the past. As one family historian has commented, most apparently modern developments in relation to marriage and family have their counterparts in the past, whether more or less distant in time. The same author notes, however, that the sheer diversity of current family arrangements is historically unique ${ }^{50}$.

Insofar as marriage and overall partnership have declined, it has to be remembered that comparison with the levels of the 1960s and early 1970s is with the peak level of marriage in twentieth century Britain. For example, the period mean age at marriage reached an all-time low in 1970 in England and Wales. It is, therefore, unsurprising in a statistical sense that marriage rates should decline and marriage age should rise in the 1970s. Nevertheless the additional delay in marriage has been very substantial indeed since the early 1980s, and marriage is now later than at any time in the last century. The growth in the frequency of cohabitation together with longer durations spent cohabiting prior to first marriage are part of the explanation for marriage delay. However, partnership itself has also been delayed, as we have seen. And so, transitions to adult statuses in general now follow a later timetable. Contributory factors include, among others, greater educational participation rates, the labour market incentives stemming from the acquisition of higher level qualifications, the difficulty of coordinating two partners' economic interests when both expect to participate in the labour market over the long term, economic uncertainty, and deteriorating labour markets ${ }^{51,52,53,54,55}$.

The proportion who at any point in time are living with a partner has been declining at all ages, due both to the later timing of marriage and partnership and because relationships are more frequently dissolved than in past decades. In the period since the 1970s, marriage breakdown initially rose but more recently appears to have stabilised and begun to decline, at least at short durations of marriage. In the most recent period 30-40 per cent of people aged 35-59 have experienced the breakdown of at least one partnership. Separation is, thus, not the majority experience, but is that of a very substantial minority at these ages. And while the majority of those separating find a new partner the net result of these trends is that the cross-sectional proportions who have previously been in a partnership, but no longer are so, have been rising.

Policy interest in cohabitation has been based to some extent on its link with marital breakdown. An extensive body of past research has reported that couples who live together before marriage are more likely to separate, once married, than those who marry directly ${ }^{56}$. However, the finding is 
far from universal, with dissolution risks being higher in some countries among those who marry directly without first living together ${ }^{5,47,57}$. Several recent studies suggest, furthermore, that when the pre-existing characteristics of those who cohabit are taken into account, the risk of marriage breakdown is no different from and may be lower among those cohabiting before marriage than among those who marry directly ${ }^{29,46,48,58}$; similar findings have been reported in relation to cohabitation itself compared with marriage ${ }^{15}$. There is some evidence also that the role of premarital cohabitation is context dependent, being associated with higher divorce risk when either uncommon or very common, in both cases because those engaging in a minority behaviour are usually select in important respects. When the practice is uncommon, those cohabiting premaritally may be less traditional, less concerned with social norms, and less risk-averse than those who marry directly; conversely, when premarital cohabitation is common, those marrying directly may have the opposite characteristics ${ }^{47}$. In line with this expectation, several studies have reported that the difference in divorce risk between marriages that are and are not preceded by a cohabitation spell has been diminishing over time ${ }^{49,59,60,61}$.

In this overview article, we have not sought to assess causal hypotheses regarding relationship breakdown - much more detailed analysis would be required for the purpose. We note, however, that the growth of cohabitation together with the upward trend in the separation risk in cohabiting unions could be seen, perhaps paradoxically, as promoting rather than competing with marriage. A first reason is that marriage rates are higher among cohabiters than among the unpartnere ${ }^{20} . A$ second point, alluded to earlier, is that the growth in cohabitation together with the rise in the proportion of cohabiters who do not marry could be linked with the stabilisation and emerging decline in marital breakdown at short durations. This could be so if cohabitation acted as a kind of marital firewall, keeping out of the married population couples whose relationship is more fragile. The hypothesis needs further investigation in a British context ${ }^{62}$.

\section{Key findings}

- The proportions of men and women who have ever married have declined and the proportions ever having cohabited have risen at all ages, in recent decades. At older ages, these trends come close to offsetting each other, but at younger ages this is not the case. The younger the age, the larger the recent decline in the proportions who have ever been in a co-residential union.

- Greater change at young ages is due primarily to a later timetable of demographic events. Men and women now enter their first partnership about two years later, on average, than in the early 1980s. Marriage is five years later, on average, with the additional delay due both to the growth in the frequency of cohabitation before marriage and to couples living together for longer before first marriage than in the recent past.

- More cohabiting couples separate without marrying, and fewer marry, than two decades ago. Cohabitation remains a relatively short term type of relationship. At the tenth anniversary of moving in together, half of cohabiting couples have married each other, just under four in ten have separated, and slightly over one in ten are still living together as a couple, on the most recent figures. 


\section{Key findings}

- There has been a decline in recent years in the proportion of marriages ending in separation or divorce by the fifth anniversary. We suggest as a hypothesis that the growth of cohabitation may have played a role in this incipient decline.

- If we consider marriage and cohabitation together, people reaching their early 40 s recently have entered some type of partnership almost as much as the most married generations of the 20th century. However, at any one time there are now fewer living with a married or cohabiting partner than in the recent past, both because of delayed entry into partnership and higher proportions separating.

\section{Acknowledgements}

This research is funded by ESRC Grant number RES-625-28-0001. The Centre for Population Change (CPC) is a joint initiative between the University of Southampton and a consortium of Scottish Universities in partnership with ONS and GROS. The findings, interpretations, and conclusions expressed in this article are entirely those of the authors and should not be attributed in any manner to ONS or NRS.

The General Household Survey is conducted by ONS. Access to the data is provided by the UK Data Archive.

The CPC GHS time series datafile on which this article is based was constructed in collaboration with Dr Ann Berrington and with the assistance of Mark Lyons Amos. We thank the Demographic Analysis Branch and the General Lifestyle Survey Branch of ONS for their help in clarifying various data issues and for providing the 2001 Census-GHS link adjustment factors used in constructing new GHS weights.

\section{Notes and References}

1 Toulemon L. 1997. Cohabitation is here to stay. Population - An English Selection 9: 11-46.

2 Cherlin AJ. 2009. The Marriage-Go-Round: The state of marriage and the family in America today. New York: Knopf.

3 Gabrielli G, Hoem JM. 2010. Italy's non-negligible cohabitational unions. European Journal of Population 26: 33-46.

4 Philipov D, Jasilioniene A. 2008. Union formation and fertility in Bulgaria and Russia: A life table description of recent trends. Demographic Research 19: 2057-2114.

5 Kiernan KE. 2002. The state of European unions: An analysis of FFS data on partnership formation and dissolution. In: Macura M, Beets G eds. Dynamics of Fertility and Partnership in Europe: Insights and lessons from comparative research, vol 1 New York and Geneva: United Nations, p 57-76. 
6 Sobotka T, Toulemon L. 2008. Changing family and partnership behaviour: Common trends and persistent diversity across Europe. Demographic Research 19: 85-138.

$7 \quad$ Prioux, F. 2009. Les couples non mariés en 2005: quelles différences avec les couples mariés? Politiques Sociales et Familiales 96: 87-95.

8 Murphy M. 2000. The evolution of cohabitation in Britain, 1960-95. Population Studies 54: 4356.

9 Figures obtained from tables online at www.britsocat.com/

10 Lewis J. 2001. Debates and issues regarding marriage and cohabitation in the British and American literature. International Journal of Law, Policy and the Family 15: 159-184.

11 Barlow A, Probert R. 2004. Regulating marriage and cohabitation: Changing family values and policies in Europe and North America-an introductory critique. Law \& Policy 26: 1-11.

12 Haskey J. 2002. One-parent families - and the dependent children living in them - in Great Britain. Population Trends 109: 46-57.

13 Wilson B. 2009. Estimating the cohabiting population. Population Trends 136: 21-27.

14 Goodman A, Greaves E. 2010. Cohabitation, marriage and child outcomes. IFS Commentary C114. London: Institute for Fiscal Studies.

15 Goodman A, Greaves E. 2010. Cohabitation, marriage and relationship stability. Briefing Note BN 107. London: Institute for Fiscal Studies.

16 See the special issue of Law and Policy, volume 26 (1), 2004.

17 Perelli-Harris B, Sanchez Gassen N. 2010. The reciprocal relationship between the state and union formation across western Europe: Policy dimensions and theoretical considerations. MPIDR Working Papers WP 2010-034. Rostock: Max Planck Institute for Demographic Research. Available at: www.demogr.mpg.de/papers/working/wp-2010-034.pdf

18 Haskey J. 1990. Identical addresses at marriage and pre-marital cohabitation: Results from linking marriage registration and census records. Population Trends 59: 20-29.

19 Haskey J. 1997. Spouses with identical residential addresses before marriage: An indicator of premarital cohabitation. Population Trends 89: 13-23.

20 Murphy M. 2000. Editorial: Cohabitation in Britain. Journal of the Royal Statistical Society Series A 163: 123-126.

21 Brown A, Kiernan K. 1981. Cohabitation in Great Britain: Evidence from the General Household Survey. Population Trends 25: 4-10.

22 Haskey J. 1995. Trends in marriage and cohabitation: The decline in marriage and the changing pattern of living in partnerships. Population Trends 80: 5-15.

23 Haskey J. 1999. Cohabitational and marital histories of adults in Great Britain. Population Trends 96: 13-24. 
24 Haskey J. 2001. Cohabitation in Great Britain: Past, present and future trends - and attitudes. Population Trends 103: 4-25.

25 Berrington A. 1992. Cohabitation in Great Britain: A comparison of estimates from the 1988/1989 General Household Survey and the 1989 Labour Force Survey. General Household Survey Newsletter No. 10: 26-37.

26 Berrington A, Diamond I. 2000. Marriage or cohabitation: A competing risks analysis of firstpartnership formation among the 1958 British birth cohort. Journal of the Royal Statistical Society Series A 163: 127-151.

27 Berrington A, Diamond I. 1999. Marital dissolution among the 1958 British birth cohort: The role of cohabitation. Population Studies 53: 19-38.

28 Ermisch J, Francesconi M. 2000. Cohabitation in Britain: Not for long, but here to stay. Journal of the Royal Statistical Society Series A 163: 153-171.

29 Steele F, Kallis C, Joshi H. 2006. The formation and outcomes of cohabiting and marital partnerships in early adulthood: The role of previous partnership experience. Journal of the Royal Statistical Society Series A 169: 757-779.

30 Berrington A, Beaujouan É, Lyons-Amos M, Ní Bhrolcháin M. forthcoming. Evaluation of the partnership histories in the Centre for Population Change consolidated dataset. Centre for Population Change Working Paper No. 12, University of Southampton.

31 Haskey J, Coleman D. 1986. Cohabitation before marriage: A comparison of information from marriage registration and the General Household Survey. Population Trends 43: 15-17.

32 Beaujouan É, Brown JJ, Ní Bhrolcháin M. 2011. Reweighting the General Household Survey 1979-2007. Population Trends 145.

33 See also Ermisch and Francesconi, note 28

34 Wilson B, Smallwood S. 2007. Understanding recent trends in marriage. Population Trends 128: 24-32.

35 Grebenik E, Rowntree G. 1963. Factors associated with the age at marriage in Britain. Proceedings of the Royal Society of London Series B, Biological Sciences 159: 178-202.

36 Heuveline P, Timberlake JM. 2004. The role of cohabitation in family formation: The United States in comparative perspective. Journal of Marriage and the Family 66: 1214-1230.

37 The period mean ages given here are standardised for age structure, that is, they are of the form $\sum x r_{x, t} / \sum r_{x, t}+0.5$, where $r_{x, t}$ is the rate of the event at age $x$ in year $t$. They can be interpreted as the mean of the age-specific event rate schedule in a particular year, or, alternatively, as the mean age at the event of a hypothetical cohort that experienced the age specific event rates observed in a particular year. The purpose of the calculation is to abstract from the distribution by age of the population at risk of a particular event in the year in question, and thus to allow year-on-year comparisons that are not influenced by differences in age structure.

38 Office for National Statistics. Births Summary and Historical Tables, England and Wales. www.ons.gov.uk 
39 Perelli-Harris B, Sigle-Rushton W, Lappegard T, Jasilioniene A, Di Giulio P, Keizer R, Koeppen K, Berghammer C, Kreyenfeld M. 2009. Examining nonmarital childbearing in Europe: How does union context differ across countries? MPIDR Working Paper WP 2009021. Rostock: Max Planck Institute for Demographic Research. Available at: www.demogr.mpg.de/papers/working/wp-2009-021.pdf

40 Note that while we would expect the figures for men and women to be close, they need not be identical. The figures in each case relate to people aged under 45 at the start of the union, and both men and women of this age may cohabit, though in differing proportions, with partners who were aged 45 and above.

41 Our estimate of 10-12 per cent of cohabiters still cohabiting at the tenth anniversary is comparable in magnitude to that of Murphy (note 8) and somewhat higher than Ermisch and Francesconi's estimates (note 28). But our figure is substantially below the 22 per cent of cohabiters at the 1991 Census who were found by Wilson and Stuchbury (note 42) to be still cohabiting with the same partner at the 2001 Census. The LS estimate is not comparable with ours as it represents the proportion of couples cohabiting at a point in time who are still living together as cohabiters 10 years later. As short unions are less likely to be current at a cross-sectional time point such as a census, the proportion who are still cohabiting 10 years later is well above the proportion of all cohabiting unions that continue as cohabitation for at least 10 years - the figure we estimate at 10-12 per cent from the GHS. For comparison with the LS, we estimate from the GHS histories that of people who were cohabiting in mid-1991 23 per cent of men and 22 per cent of women were still cohabiting 10 years later, essentially the same as the LS estimate.

42 Wilson B, Stuchbury R. 2010. Do partnerships last? Comparing marriage and cohabitation using longitudinal census data. Population Trends 139: 37-63.

43 Wilson B, Smallwood S. 2008. The proportion of marriages ending in divorce. Population Trends 131: 28-36.

44 We confine the GHS figures in Table 5 to women, as the GHS data on the frequency of separation in marriages reported by men appear to be inaccurate, being too low and inconsistent with vital registration data on divorce.

45 Tables provided by Demographic Analysis Branch, Office of National Statistics: Cumulative percentage of marriages ending in divorce by year of marriage (1963-2008) and by anniversary, England and Wales.

46 Klijzing E. 1992. 'Weeding' in the Netherlands: First-union disruption among men and women born between 1928 and 1965. European Sociological Review 8: 53-70.

47 Liefbroer AC, Dourleijn E. 2006. Unmarried cohabitation and union stability: Testing the role of diffusion using data from 16 European countries. Demography 43: 203-221.

48 Kulu H, Boyle PJ. 2010. Premarital cohabitation and divorce: Support for the 'trial marriage' theory? Demographic Research 23: 879-904. 
49 Hewitt B, De Vaus D. 2009. Change in the association between premarital cohabitation and separation, Australia 1945-2000. Journal of Marriage and the Family 71: 353-361.

50 Coontz S. 2004. The world historical transformation of marriage. Journal of Marriage and the Family 66: 974-979.

51 Berrington A, Stone J, Falkingham J. 2009. The changing living arrangements of young adults in the UK. Population Trends 138: 27-37.

52 Billari FC, Liefbroer AC, Philipov D. 2006. The postponement of childbearing in Europe. Driving forces and implications. Vienna Yearbook of Population Research 4: 1-17.

53 Oppenheimer VK. 1988. A theory of marriage timing. American Journal of Sociology 94: 563591.

54 Kalmijn M. 2011. The influence of men's income and employment on marriage and cohabitation: Testing Oppenheimer's theory in Europe. European Journal of Population. Available at: www.springerlink.com/content/102885/.

55 Adsera A. 2011. Where are the babies? Labor market conditions and fertility in Europe. European Journal of Population 27: 1-32.

56 For references to recent and past sources on the subject see Liefbroer and Dourleijn, note 47 and Kulu and Boyle, note 48.

57 Svarer M. 2004. Is your love in vain? Another look at premarital cohabitation and divorce. Journal of Human Resources 39: 523-535.

58 Lillard LA, Brien MJ, Waite LJ. 1995. Premarital cohabitation and subsequent marital dissolution: A matter of self-selection? Demography 32: 437-457.

59 Schoen R. 1992. First unions and the stability of first marriages. Journal of Marriage and the Family 54: 281-284.

60 De Vaus D, Qu L, Weston R. 2005. The disappearing link between premarital cohabitation and subsequent marital stability, 1970-2001. Journal of Population Research 22: 99-118.

61 Reinhold S. 2010. Reassessing the link between premarital cohabitation and marital instability. Demography 47: 719-733.

62 A study in the US found little evidence of such an aggregate effect. See Goldstein JR. 1999. The leveling of divorce in the United States. Demography 36: 409-414 


\section{Appendix}

\section{Table A1 Per cent ever having experienced each type of partnership by specified exact ages, by sex. Great Britain, 1980-84 to 2004-07. GHS 2000-2007}

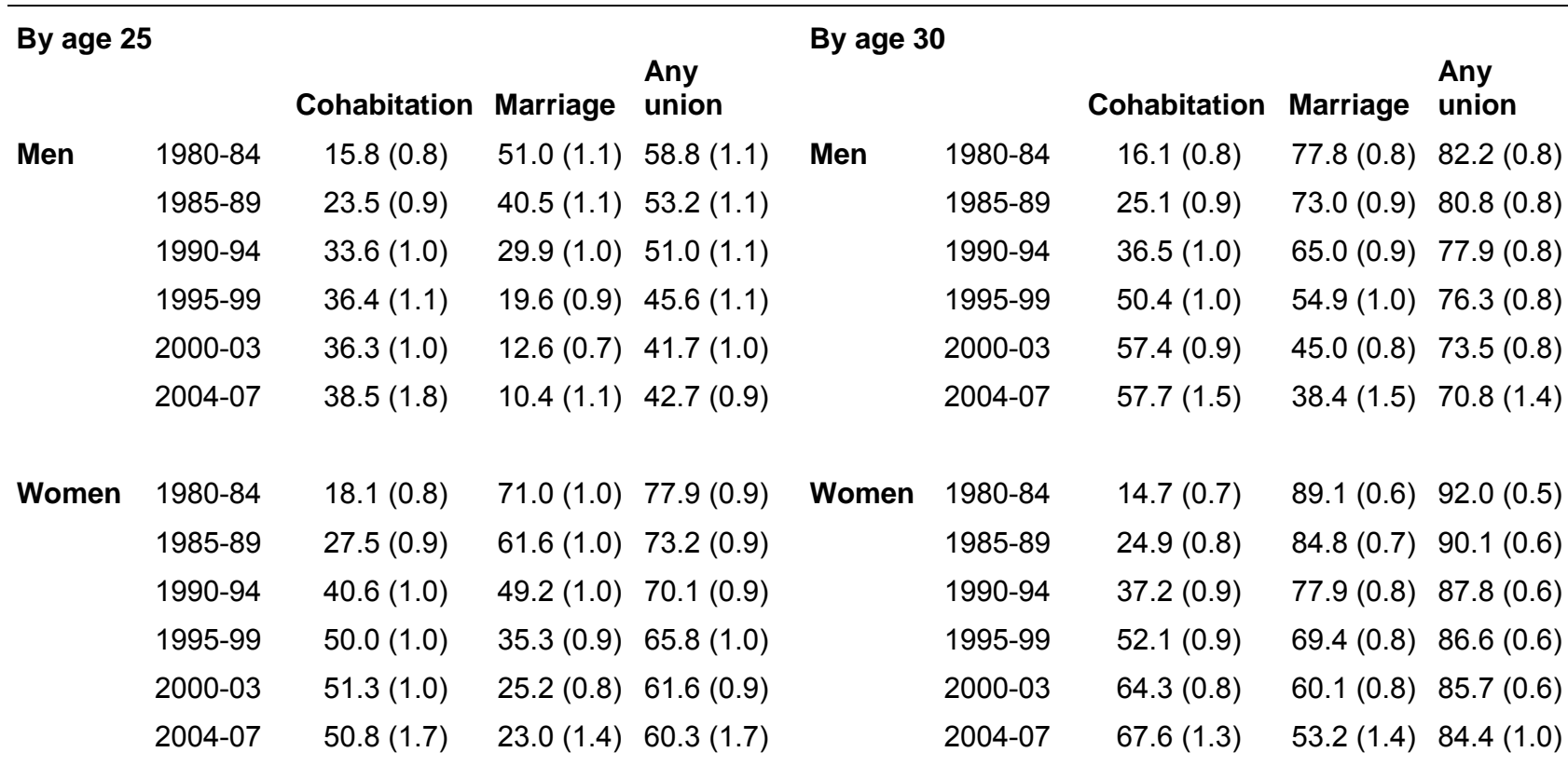

By age 35

$1985-89$

1990-94

1995-99

2000-03

2004-07

1980-84

1985-89

1990-94

1995-99

2000-03

2004-07
Cohabitation Marriage Any
$22.1(0.9) \quad 84.6(0.8) \quad 88.6(0.7)$

$32.1(1.1) \quad 81.0(0.9) \quad 87.8(0.8)$

$45.6(1.1) \quad 74.3(0.9) \quad 86.2(0.8)$

$58.6(0.9) \quad 67.6(0.9) \quad 85.7(0.7)$

$66.0(1.5)$

$62.6(1.5) \quad 85.6(1.1)$
By age 40

Men

1980-84

1985-89

1990-94

1995-99

2000-03

2004-07

\section{Any \\ Cohabitation Marriage union}

$\begin{array}{lll}26.3(1.0) & 87.3(0.7) & 91.1(0.6) \\ 36.4(1.1) & 84.2(0.8) & 90.5(0.7) \\ 47.4(1.0) & 80.1(0.8) & 89.7(0.6) \\ 57.5(1.6) & 75.9(1.3) & 89.3(1.0)\end{array}$

Women 1980-84

1985-89

1990-94

1995-99

$22.8(0.9) \quad 93.7(0.5) \quad 96.2(0.4)$

$34.9(1.0) \quad 90.9(0.6) \quad 95.2(0.5)$

2000-03 $45.4(0.9) \quad 87.2(0.6) \quad 94.1(0.4)$

2004-07 $53.4(1.5) \quad 84.2(1.1) \quad 94.0(0.7)$

\section{Notes}

1. Samples: by age 25: experience of union by 25th birthday among those aged 25-29 in each period; by age 30 : experience of union by 30th birthday among those aged 30-34 in period; etc.

2. 2 x standard error is given in parentheses. Sample sizes are smaller in 2004-07 both because only one wave's data is used in each of the GHS rounds of 2006 and 2007 and because cumulative incidence in the most recent period is based only on the GHS 2004-2007 histories, whereas the figures for earlier years are based on the retrospective histories collected in GHS rounds 2000-07.

Source: CPC GHS time series data file 